\title{
Brucella melitensis omp31 Mutant Is Attenuated and Confers Protection Against Virulent Brucella melitensis Challenge in BALB/c Mice
}

\author{
L Verdiguel-Fernández ${ }^{1}$, R Oropeza-Navarro ${ }^{2}$, Adolfo Ortiz ${ }^{3}$, MG Robles-Pesina ${ }^{4}$, \\ J Ramírez-Lezama ${ }^{5}$, A Castañeda-Ramírez ${ }^{6}$, and A Verdugo-Rodríguez ${ }^{1 *}$ \\ 'Laboratorio de Microbiología Molecular, Departamento de Microbiología e Inmunología, Facultad de Medicina \\ Veterinaria y Zootecnia, Universidad Nacional Autónoma de México, Avenida Universidad 3000, colonia UNAM \\ CU, Coyoacán C.P 04510, CdMx, México \\ ${ }^{2}$ Departamento de Microbiología Molecular, Instituto de Biotecnología, Universidad Nacional Autónoma de \\ México, Cuernavaca, Morelos, México \\ ${ }^{3}$ Unidad de Bioseguridad de Brucella, Departamento de Microbiología e Inmunología, Facultad de Medicina \\ Veterinaria y Zootecnia, Universidad Nacional Autónoma de México, Coyoacán, México \\ ${ }^{4}$ Centro Nacional de Servicios de Diagnóstico en Salud Animal (CENASA), Servicio Nacional de Sanidad, Inocuidad \\ y Calidad Agroalimentaria, Tecámac, México \\ ${ }^{5}$ Departamento de Patología, Facultad de Medicina Veterinaria y Zootecnia, Universidad Nacional Autónoma de \\ México, Coyoacán, CdMx, México \\ ${ }^{6}$ Departamento de Zootecnia, Universidad Autónoma de Chapingo, Texcoco, México
}

For control of brucellosis in small ruminants, attenuated B. melitensis Rev1 is used but it can be virulent for animals and human. Based on these aspects, it is essential to identify potential immunogens to avoid these problems in prevention of brucellosis. The majority of OMPs in the Omp25/31 family have been studied because these proteins are relevant in maintaining the integrity of the outer membrane but their implication in the virulence of the different species of this genus is not clearly described. Therefore, in this work we studied the role of Omp31 on virulence by determining the residual virulence and detecting lesions in spleen and testis of mice inoculated with the B. melitensis LVM31 mutant strain. In addition, we evaluated the conferred protection in mice immunized with the mutant strain against the challenge with the $B$. melitensis $B m 133$ virulent strain. Our results showed that the mutation of omp 31 caused a decrease in splenic colonization without generating apparent lesions or histopathological changes apparent in both organs in comparison with the control strains and that the mutant strain conferred similar protection as the $B$. melitensis Rev1 vaccine strain against the challenge with $B$. melitensis $B m 133$ virulent strain. These results allow us to conclude that Omp31 plays an important role on the virulence of $B$. melitensis in the murine model, and due to the attenuation shown by the strain, it could be considered a vaccine candidate for the prevention of goat brucellosis.

Received: August 29, 2019 Accepted: January 12, 2020

First published online: January 17,2020

*Corresponding author Phone: +52-1-555622-58-97 E-mail: antoverduro@hotmail. com

pISSN 1017-7825 elSSN 1738-8872

Copyright(C) 2020 by The Korean Society for Microbiology and Biotechnology
Keywords: Brucella melitensis, omp31, virulence, vaccines, immunity

\section{Introduction}

The microorganisms of the genus Brucella are facultative intracellular pathogens that infect a great variety of mammals, producing epizootic abortion in animals and a febrile septicemic disease in humans called Malta fever or undulant fever, one of the zoonotic diseases of worldwide importance [1]. Currently, ten species of the genus Brucella have been recognized, although $B$. melitensis is the most isolated and virulent species in humans while also being the etiological agent of goat brucellosis, which causes heavy economic losses as it leads to infertility in males, abortions and mastitis in females, and arthritis in animals [2]. Therefore, vaccination has to be considered the fundamental tool to block the spread of brucellosis among animals. B. melitensis Rev1 vaccine is recognized as the most effective vaccine strain for the control and prevention of goat and sheep brucellosis, however, its application has adverse effects since it can cause abortions when pregnant animals are vaccinated. Furthermore, lactating females can secrete the vaccine strain through milk, infecting others animals; the vaccine also interferes 
Table 1. Bacterial strains.

\begin{tabular}{llll}
\hline \multicolumn{1}{c}{ Bacterial strain } & \multicolumn{1}{c}{ Relevant genotype } & \multicolumn{1}{c}{ Relevant characteristic } & Origin \\
\hline $\begin{array}{l}\text { Brucella melitensis } \\
\text { biotype } 1 \mathrm{Bm} 133\end{array}$ & $\begin{array}{l}\text { Mexican reference } \\
\text { strain (wild type) }\end{array}$ & Smooth virulent Brucella strain & $\mathrm{MML}^{\mathrm{a}}$ \\
Brucella melitensis Rev1 & Vaccine reference strain & $\begin{array}{l}\text { Smooth attenuated Brucella strain with a } \\
\text { Streptomycin resistance }\end{array}$ & MML $^{\mathrm{a}}$ \\
Brucella melitensis LVM31 & $\begin{array}{l}\text { omp31::Kan } \\
\text { (mutant strain) }\end{array}$ & $\begin{array}{l}\text { Brucella melitensis biotype 1 Bm133 with a } \\
\text { Kanamycin resistance cassette inserted }\end{array}$ & $\begin{array}{l}\text { Verdiguel } \text { et al. } \\
\text { into the SalI site of omp31 }\end{array}$ \\
\end{tabular}

${ }^{a}$ MML, Molecular Microbiology Lab, Immunology and Microbiology Department, UNAM.

with serological diagnosis, besides being virulent for humans [3-5]. Brucella spp. are short rods, gram negative, immobile, not sporulated and without capsule, so this pathogen does not have classic virulence factors like other bacteria. Based on these findings, several studies have concluded that many aspects of Brucella virulence are related to the characteristics of its outer membrane $(\mathrm{OM})$. OM of Brucella has particular properties: it is resistant to the action of cationic peptides (lysozyme, lactoferrin, defensins or cathelicidins), detergents and non-immune serum [6-8]. The major components of Brucella OM are lipopolysaccharide (LPS) and outer membrane proteins (OMPs). OMPs are exposed on the surface of the bacteria and come into direct contact with cells and effectors of the immune response of host organism [9]. Therefore, the study on this field is of great interest, since it can provide a broader knowledge about the mechanisms of host-parasite interaction used by this genus, which could also allow the development of new attenuated vaccines better than the existing ones [10,11]. In recent years, several investigations have been carried out in order to determine the influence of the Omp25/Omp31 family on virulence of Brucella [12]. Regarding Omp31, several studies have shown that it is about 32\% identical with HbpA, which belongs to the hemin-binding protein (Hbp) family of Bartonella quintana [13]. In this respect, several studies have also been performed to verify that Omp31 of B. suis possesses some capacity to bind hemin, and that the expression of the gene that encodes it, is induced when B. suis is grown under limited iron conditions [14]. It is also known that Omp31 is not necessary for the virulence of $B$. abortus, since in this species the gene coding for it is not present due to a deletion in its genome $[15,16]$. Besides, it has been shown that virulence of $B$. melitensis Rev1 vaccine strain in mice is not affected after omp31 deletion [17], although it should be noted that Rev.1 strain has a lower level of omp 31 expression than that present in the B. melitensis $16 \mathrm{M}$ strain under laboratory conditions, and this fact can only be related to strain attenuation [18]. Other reports showed that the absence of this protein in the outer membrane of the B. ovis PA strain, although it reduces by one logarithm the maximum levels of splenic colonization of the bacteria in mice, its persistence in spleen is not diminished [8]. In a recent study, Verdiguel et al. 2017 demonstrated that the mutation of omp 31 altered the outer membrane properties of B. melitensis and caused a significant decrease in the internalization, survival and intracellular replication of the bacterium in murine macrophages J774.A1 and in HeLa cells [19], thus suggesting Omp31 could play a relevant role in the virulence of the bacteria. To verify this hypothesis, we aimed in this work to determine the effect of omp31 mutation on B. melitensis virulence in a murine model and evaluate the protection conferred in mice immunized with the mutant strain.

\section{Materials and Methods}

Bacterial Strains and Growth Conditions

The strains used in this work are listed in Table 1 . Brucella strains were cultured at $37^{\circ} \mathrm{C}$ in a $5 \% \mathrm{CO}_{2}$ atmosphere for $72 \mathrm{~h}$. They were typically propagated in Brucella broth (BB; Difco Laboratories, USA) or Brucella agar (BA; Difco Laboratories), both supplemented with $0.3 \%$ yeast extract (YE; Difco Laboratories) and $5 \%$ fetal bovine serum (FBS; GIBCO-BRL Life Technologies, Germany) (BB-YE-FBS and BA-YE-BFS). Prior to use, the strains were characterized by PCR and biochemical tests for the identification of microorganisms of the genus Brucella as well as Triple Sugar Iron (TSI), citrate, urea, hydrogen sulfide-indole-motility (SIM)), and Gram stain. Brucella were provided by MML (Molecular Microbiology Laboratory, Immunology and Microbiology Department, FMVZ-UNAM, Mexico). B. melitensis LVM31 was constructed by Verdiguel et al. [19].

Table 2. Residual virulence determination in mice inoculated with Brucella strains.

\begin{tabular}{|c|c|c|c|}
\hline \multicolumn{2}{|r|}{ Female } & \multicolumn{2}{|r|}{ Male } \\
\hline Group 1 & $\begin{array}{l}10 \text { female BALB/c mice inoculated with } \\
\text { B. melitensis wild-type strain }\end{array}$ & Group 1 & $\begin{array}{l}10 \text { male } \mathrm{BALB} / \mathrm{c} \text { mice inoculated with } \\
\text { B. melitensis wild-type strain }\end{array}$ \\
\hline Group 2 & $\begin{array}{l}10 \text { female BALB/c mice inoculated with } \\
\text { B. melitensis } \text { Revl vaccine strain }\end{array}$ & Group 2 & $\begin{array}{l}10 \text { male } \mathrm{BALB} / \mathrm{c} \text { mice inoculated with } \\
\text { B. melitensis } \mathrm{Rev} 1 \text { vaccine strain }\end{array}$ \\
\hline Group 3 & $\begin{array}{l}10 \text { female BALB/c mice inoculated with } \\
\text { B. melitensis LVM } 31 \text { mutant strain }\end{array}$ & Group 3 & $\begin{array}{l}10 \text { male } \mathrm{BALB} / \mathrm{c} \text { mice inoculated with } \\
\text { B. melitensis LVM } 31 \text { mutant strain }\end{array}$ \\
\hline Group 4 & 10 female BALB/c mice inoculated with PBS & Group 4 & 10 male BALB/c mice inoculated with PBS \\
\hline
\end{tabular}

Female and male BALB/c mice were inoculated with approximately $5 \times 10^{5} \mathrm{CFU}$ of $B$. melitensis strains. 
Table 3. Mice immunized with vaccine strains for evaluating the protection conferred against challenge of B. melitensis wild type.

$\begin{array}{ll}\text { Group } 1 & 10 \text { female BALB/C mice immunized with } 1 \times 10^{9} \mathrm{CFU} \text { of } B \text {. melitensis LVM31 } \\ \text { Group 2 } & 10 \text { female BALB/C mice immunized with } 1 \times 10^{9} \mathrm{CFU} \text { of } B \text {. melitensis Rev1 vaccine strain } \\ \text { Group } 3 & 10 \text { female BALB/C mice immunized with PBS }\end{array}$

\section{Experimental Animals and Ethical Guidelines}

Corresponding groups are listed in Tables 2,3, and 4. Representative groups of mice were required so that blood sampling and organ harvesting could be done at different times in order to evaluate residual virulence and the protection conferred by the mutant strain in comparison with the vaccine strain in order to perform the statistical analysis of the results. Mice were donated by the National Center for Diagnostic Services in Animal Health (CENASA).

Every day the health and behavior of mice were evaluated, while signs of any infectious disease were investigated. If the animals presented any alteration of the aforementioned parameters, they were euthanized. Mice were euthanized by cervical dislocation according to NOM-062-ZOO-1999 (Mexico) and the carcasses were incinerated according to NOM-087-ECOL-SSA1-2002 (Mexico).

Once the animals were euthanized, the spleen was removed under aseptic conditions. Each spleen was homogenized in sterile bags with $0.5 \mathrm{ml}$ of PBS, serial dilutions were then made $(\mathrm{v} / \mathrm{v})$ and $20 \mu \mathrm{l}$ of each homogenate was plated in triplicate and by double repetition per mouse on supplemented Brucella agar. Plates were incubated at $37^{\circ} \mathrm{C}$ under an atmosphere of $5 \% \mathrm{CO}_{2}$ until the $\mathrm{CFU}$ count could be made [20]. This methodology was carried out to determine the residual virulence and protection conferred in mice inoculated with Brucella strains.

Residual Virulence Determination in Mice Inoculated with Brucella Strains

Groups of 10 female and 10 male BALB/c mice of 8 weeks in age were inoculated intraperitoneally with approximately $5 \times 10^{5} \mathrm{CFU}$ of $B$. melitensis wild type, B. melitensis Rev1 vaccine and with $B$. melitensis LVM31 mutant strains suspended in $0.2 \mathrm{ml}$ of PBS. A negative control group of 10 female and 10 male BALB/c mice was inoculated with $0.2 \mathrm{ml}$ of PBS (Table 2). Counts of CFUs from the spleen of 2 female mice per strain were determined at $3,6,9,12$, and 15 weeks post inoculation, while counts of CFUs from the spleen of 2 male mice per strain were determined at 4,8 , and 12 weeks post inoculation.

Evaluation of Conferred Protection of Mice Immunized with Mutant and Vaccine Strains against Challenge with the Virulent B. melitensis Bm133 Strain

Groups of 10 8-week-old female BALB/c mice were immunized subcutaneously with $1 \times 10^{9} \mathrm{CFU}$ of $B$. melitensis LVM31 mutant and B. melitensis Rev1 vaccine strains in a $0.2 \mathrm{ml}$ suspension [21, 22]. A control group of 10 unvaccinated mice was inoculated with $0.2 \mathrm{ml}$ of PBS (Table 3). Thirty days after immunization mice were challenged intraperitoneally with $10^{6} \mathrm{CFU} /$ mouse of the B. melitensis $\mathrm{Bm} 133$ wild-type strain[23]. Two mice were euthanized by cervical dislocation at weeks three, six and nine after challenge and spleens were collected from the mice and processed individually to quantify the CFUs per mouse.

Evaluation of Residual Virulence in Pups Born of Females Inoculated with Brucella Strains

Groups of 3 female BALB/c mice of 10 weeks of age were inoculated intraperitoneally with a $0.2 \mathrm{ml}$ suspension $\left(5 \times 10^{5} \mathrm{CFU}\right)$ of the wild-type, vaccine, and mutant strains or with $0.2 \mathrm{ml}$ of PBS (Table 3$)$. Seven days post inoculation; a male $\mathrm{BALB} / \mathrm{c}$ mouse was introduced into the cages corresponding to each group. The male mouse was removed when the pregnant females started giving birth to avoid cannibalistic behavior. The offspring was separated three weeks after birth and confined in a different cage. At six weeks of age, they were euthanized and random samples of spleen were taken from three mice per group; spleens were processed as mentioned in methodology to determine splenic colonization of the offspring by CFU counting.

Evaluation of Organ Lesions of BALB/c Mice Inoculated with Brucella Strains

At week 15 post infection, two mice were euthanized from each group of animals to take samples of spleen and testicles if a mouse was male; the tissues were fixed in $10 \%$ formalin $(\mathrm{pH} 7.2)$ and stained with hematoxylin and eosin (H \& E); finally they were analyzed in a photonic force microscope to look for histopathological lesions [24].

\section{Statistical Analysis}

Statistical analysis was performed using GraphPad Prism 7.0 (GraphPad software, USA). The data from assays for bacterial colonization in $\mathrm{BALB} / \mathrm{c}$ mice at different time points and from efficacy studies were expressed as the

Table 4. Corresponding groups for evaluating residual virulence in pups born of females inoculated with Brucella strains.

$\begin{array}{ll}\text { Group } 1 & 10 \text { female BALB/C mice inoculated with } B \text {. melitensis wild-type strain } \\ \text { Group } 2 & 10 \text { female BALB/C mice inoculated with } B \text {. melitensis Rev1 vaccine strain } \\ \text { Group 3 } & 10 \text { female BALB/C mice inoculated with B. melitensis LVM31 mutant strain } \\ \text { Group } 4 & 10 \text { female BALB/C mice inoculated with PBS }\end{array}$


A

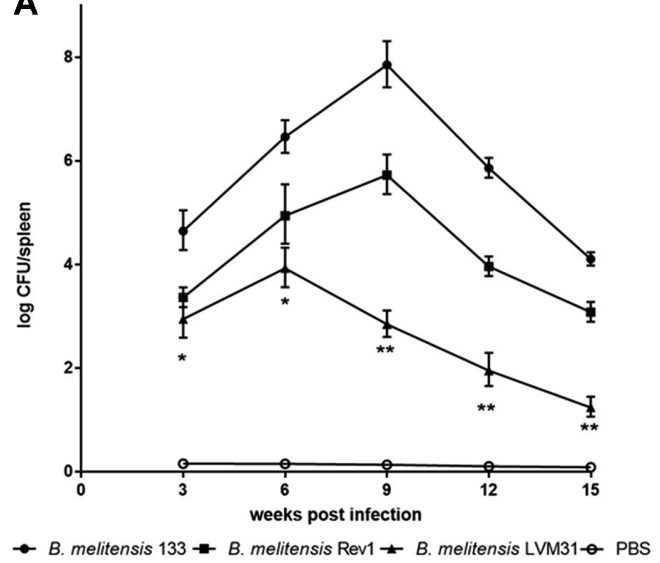

B

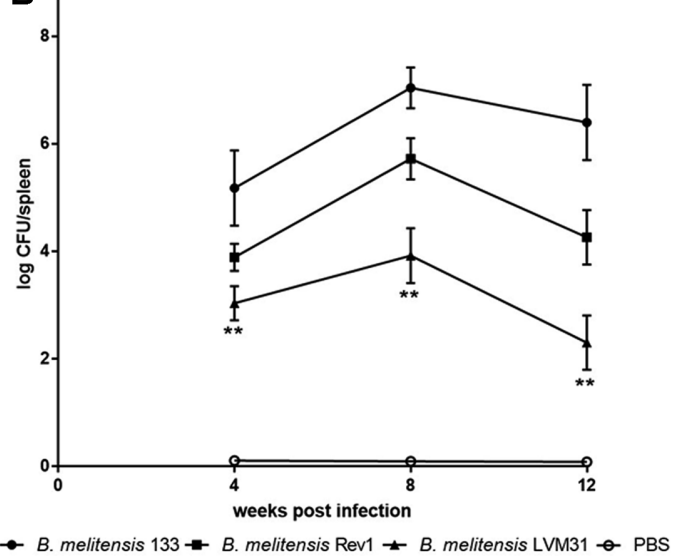

Fig. 1. Residual virulence determination in mice inoculated with Brucella strains. (A) Splenic colonization of $\mathrm{BALB} / \mathrm{c}$ female mice inoculated with Brucella strains. (B) Splenic colonization of male BALB/c mice inoculated with Brucella strains. Significant differences between LVM31 mutant strain and Bm133 are indicated by ${ }^{*}(p<0.05),{ }^{* *}(p<0.01)$.

mean $\log \mathrm{CFU} \pm \mathrm{SD}$ for each group and analyzed by Student's $t$ test. $P$ values of $<0.05\left(^{*}\right)$ and $p$ values of $<0.01\left(^{* *}\right)$ were considered statistically significant.

\section{Results}

\section{Residual Virulence Determination in Mice Inoculated with Brucella Strains}

We evaluated the role of Omp31 on Brucella virulence in a murine model. Therefore, BALB/c mice were inoculated with $B$. melitensis LVM31 mutant strain in order to evaluate the residual virulence by determining the splenic colonization in comparison with mice inoculated with B. melitensis Bm133 virulent strain and B. melitensis Rev1 vaccine strain.

The results of this work showed that there was a statistically significant decrease $(p<0.01)$ in splenic colonization in female mice inoculated with $B$. melitensis LVM31 mutant strain at 3, 6, 9, 12, and 15 weeks post infection compared with $B$. melitensis Bm133 wild-type strain, whereas in comparison with B. melitensis Rev1 vaccine strain there was a statistically significant decrease $(p<0.01)$ in the splenic colonization at 9,12 , and 15 weeks post infection (Fig. 1A).

Regarding male mice, it was shown that there was a statistically significant decrease $(p<0.01)$ in splenic colonization in mice inoculated with $B$. melitensis LVM31 mutant strain at 4, 8, and 12 weeks post infection compared to B. melitensis Bm133 virulent strain and with B. melitensis Revl vaccine strain (Fig. $1 \mathrm{~B}$ ). In both assays, the mice inoculated with $0.2 \mathrm{ml}$ of PBS (negative control) had no colony growth in the culture media.

Based on these findings, we were able to verify the hypothesis that the Omp31 plays an important role in the virulence of $B$. melitensis in the murine model.

\section{Evaluation of the Protection Conferred in Mice Immunized with Vaccine Strains}

The objective of this experiment was to determine if $B$. melitensis LVM31 mutant strain was able to protect female $\mathrm{BALB} / \mathrm{c}$ mice against challenge of $B$. melitensis $\mathrm{Bm} 133$ wild-type strain. Mice immunized subcutaneously with $0.2 \mathrm{ml}\left(1 \times 10^{9} \mathrm{CFU} / \mathrm{ml}\right)$ of LVM31 mutant strain, the Rev1 vaccine strain (positive control) or with $0.2 \mathrm{ml}$ of sterile PBS (negative control), were challenged 30 days after vaccination with the virulent Bm133 strain. Spleen samples were taken from two mice per group and splenic colonization was determined at 3,6, and 9 weeks post challenge. The CFU count was performed in triplicate and by repetition. The results represent the mean \pm standard deviation of the log CFU/ml.

The results of this work showed that there was a decrease in splenic colonization in mice immunized with the vaccine strain compared to mice immunized with the mutant strain. Because there was no statistically significant difference between these strains, these results allow us to conclude that the mutant strain of B. melitensis LVM31 conferred a protection similar to the $B$. melitensis Rev1 vaccine strain against the challenge with the virulent B. melitensis Bm133 strain (Fig. 2).

Evaluation of Residual Virulence in Pups Born of Females Inoculated with Brucella Strains

The objective of this experiment was to determine splenic colonization in BALB/c six-week-old mice born from $\mathrm{BALB} / \mathrm{c}$ females inoculated with Brucella strains or PBS.

The results obtained in this work showed a statistically significant decline $(p<0.05)$ in splenic colonization on mice born from females inoculated with B. melitensis LVM31 mutant strain compared to females inoculated with Rev1 vaccine strain and Bm133 wild-type strain. Based on these results it can be concluded that the transmission of the bacteria from the mothers to the offspring was statistically significantly reduced in the mice inoculated with the LVM31 mutant strain in comparison with Rev1 and Bm133 strains (Fig. 3). It is important to clarify that with 


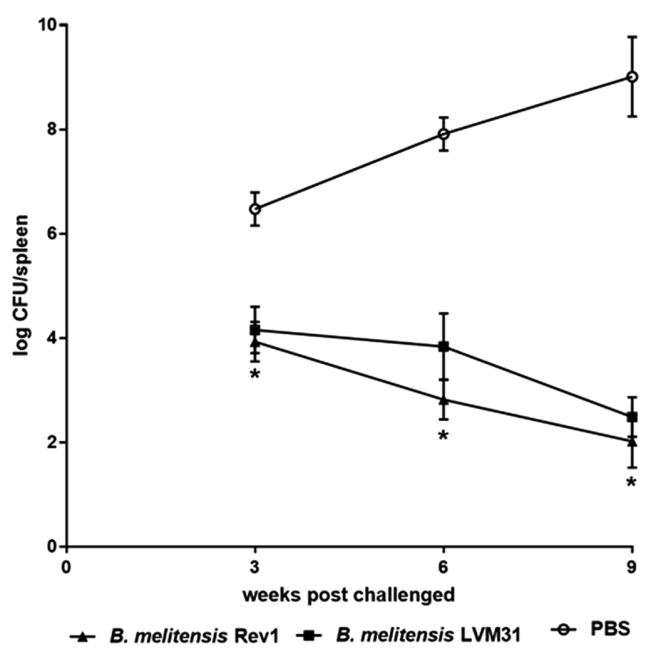

Fig. 2. Evaluation of the conferred protection of female Balb/c mice immunized with LVM31 mutant strain and Rev1 vaccine strain against the challenge with the virulent $B$. melitensis Bm133 strain. The asterisks indicate significant differences between mice immunized with PBS and mice immunized with LVM31 mutant strain $\left({ }^{*} p<0.05\right)$.

these results, we can not determine if the mechanisms of propagation of the bacteria were by vertical or horizontal transmission. Therefore, other studies will have to be carried out to determine the transmission mechanism.

\section{Determination of Organ Lesions of BALB/c Mice Inoculated with Brucella Strains}

After demonstrating that the mutation of omp31 generated a decrease in splenic colonization as a consequence of attenuation in the virulence of the bacterium on murine model, samples of spleen and testicles (in case of males) of two mice were taken from each group 15 weeks post inoculation with Brucella strains in order to determine histopathological lesions of the organs.

The results of this analysis revealed that the spleens of mice inoculated with PBS (Fig. 4D) and with B. melitensis LVM31 mutant strain (Fig. 4A) showed no apparent histopathological changes while the spleens of mice inoculated with vaccine strain (Fig. 4B) and wild-type strain (Fig. 4C) showed diffuse discrete lymphoid atrophy in white pulp with moderate megakaryocytes in red pulp and diffuse moderate lymphoid atrophy with abundant megakaryocytes, respectively.

On testes of mice inoculated with all Brucella strains, there were no apparent histopathological changes in any of the cases (data not shown).

\section{Discussion}

Brucella is a facultative intracellular pathogen. As a particular feature, smooth Brucella species can invade, survive and multiply in professional phagocytic cells such as macrophages and dendritic cells, as well as non-phagocytic cells such as trophoblast cells and epithelial cells (HeLa cells) [25, 26]. Interestingly, Brucella spp. do not have classical virulence factors like other bacteria and several investigations have focused on identifying the role of the Omp25/Omp31 family in virulence of the genus Brucella [27]. The survival and replication of Brucella within macrophages, which represents the main host cells for this pathogen, will provide this microorganism protection

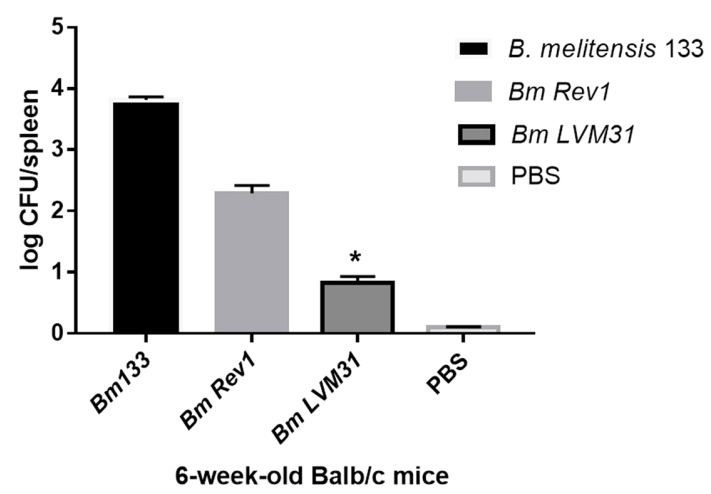

Fig. 3. Evaluation of the virulence of offspring born of females inoculated with strains of Brucella spp. Significant difference between LVM31 mutant strain and Bm133 strain is indicated by ${ }^{\star}(p<0.05)$. 

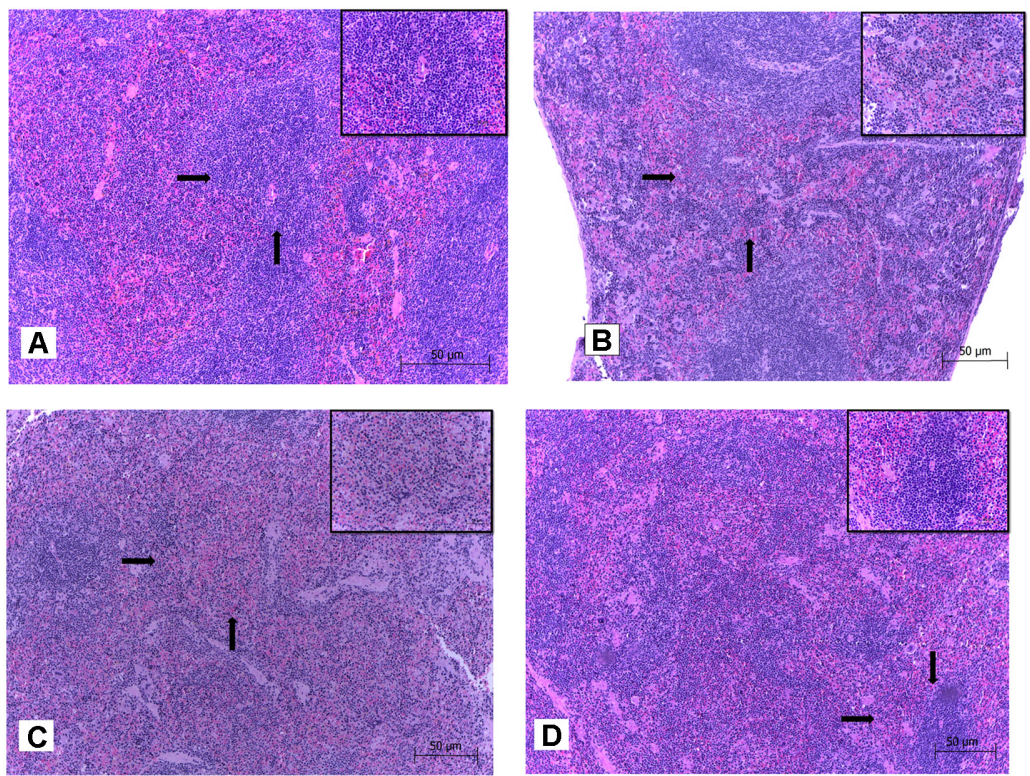

Fig. 4. Spleen samples of mice inoculated with Brucella strains. (A) Mouse spleen inoculated with B. melitensis LVM31, (arrows point to spleen section showing organization of lymphoid follicles without apparent histopathological changes). (B) Mouse spleen inoculated with B. melitensis Rev1 (arrows point to spleen section showing disorganization of the lymphoid follicles; area in the box indicates diffuse moderate atrophy of lymphoid cells in white pulp with few megakaryocytes. (C) Mouse spleen inoculated with B. melitensis Bm133 (arrows point to spleen section showing discrete disorganization of the lymphoid follicles; in the box there is discrete atrophy of lymphoid cells in white pulp and no presence of megakaryocytes). (D) Mouse spleen inoculated with PBS (arrows point to spleen section showing organization of lymphoid follicles without apparent histopathological changes).

against the complement and antibodies during their dissemination by the host, and also the ability to maintain themselves for long periods of time in the organ affected, with the consequent chronicity of the infection [28]. This feature of Brucella strains in the smooth phase implies a complex process in which this pathogen interferes with the functions of the host cell, even controlling its own intracellular traffic. In this aspect it is known that when the expression of some proteins of macrophage are inhibited, the intracellular survival of $B$. melitensis is reduced in the early stages of phagocytosis [29]. Thus, when a smooth species of Brucella is phagocytized by the macrophage, it enters in an endocytic path, avoiding the hydrolytic degradation by fusion with the lysosomes, allowing its intracellular survival in the early stages of infection [30,31]. Therefore, it is known that virulence of Brucella is associated with survival in phagocytic cells [25]. This could explain the results obtained by our research group, in which we observe a relationship between the reduction of the internalization of B. melitensis LVM31 mutant strain and a decrease in the survival and intracellular replication of the bacterium from 4 hours until the 72 hours post infection in both murine macrophages and HeLa cells. Based on these results, we conclude that Omp31 plays a key role in the invasion and intracellular multiplication capacity of B. melitensis Bm133[19].

Once we identified that the Omp31 protein plays an important role in the integrity of outer membrane properties and in the intracellular survival of $B$. melitensis in macrophages and epithelial cells, we further investigated what the effect of the mutation of omp 31 would be on virulence of the bacterium in a murine model [19].

Although mice are not natural hosts of Brucella spp., they are the experimental laboratory model most used to study the virulence of Brucella in vivo [32]. In this model, Brucella can infect multiple tissues, including spleen and liver. During the chronic stages of infection, a recent study using bioluminescent Brucella strains found that bacteria target the salivary glands, which could be related to human infection, where inoculation occurs by ingestion of contaminated food. In addition, the mice presented a chronic infection of the tail joints with Brucella similar to osteoarticular brucellosis in animals and humans $[33,34]$. The course of murine brucellosis depends on the virulence of the bacterial strain, the dose and the route of inoculation, as well as breed, genetic background, age, sex and physiological state of the mice. Therefore, more investigations are needed to clarify these experimental variables [32].

The replication profiles of the Brucella in spleen are highly reproducible and are developed in four phases: i), initiation or colonization of the spleen (first $48 \mathrm{~h}$ ); ii), acute phase, from the third day until the moment when the bacteria reach maximum numbers; iii) chronic constant phase, where the bacterial numbers are plateaus; and iv), phase of chronic decline, during which bacteria of the genus Brucella are eliminated. This pattern shows clearly pathophysiological signs and is sensitive to small variations in virulence, which makes it possible to evaluate the attenuation when fully virulent bacteria are used as controls [23]. Based on these investigations we included different variables in the present study. We used two control strains of Brucella melitensis with different virulence 
degrees in order to determine the splenic colonization of B. melitensis LVM31 mutant strain in both male and female BALB/c mice compared to the control strains. Another variable that we included in the study was the physiological state of the animals, because in the present study we inoculated pregnant female mice with the different Brucella strains in order to determine the splenic colonization of the offspring since several studies have reported both vertical and horizontal transmission in offspring of experimentally infected females [35]. Therefore, we hypothesized whether the mutation of omp 31 would cause a decrease in the propagation of LVM31 mutant strain through these transmission routes.

The results obtained in this work showed that the absence of the Omp31 protein caused a decrease in splenic colonization in both male and female Balb/c mice. In addition, organs of the mice inoculated with LVM31 mutant strain did not present lesions or apparent histopathological changes compared to mice inoculated with the control strains. These results are very similar to those obtained in other studies, where they demonstrated that the absence of this protein on outer membrane of the $B$. ovis PA strain, although it reduces by one logarithm the maximum levels of splenic colonization of the bacterium in mouse, it does not diminish its persistence in spleen $[8,36,37]$.

Regarding the evaluation of the degree of propagation with the mutant strain in mice under study, our results showed that there was a decrease in splenic colonization in the mice born from the females inoculated with B. melitensis LVM31 mutant strain in comparison with the control strains.

These results could be explained because Omp31 has also been attributed an immunomodulatory role in B. melitensis 16M [38], as well as porin function characteristics [39] and of binding to heme groups in B. ovis, B. melitensis and B. suis [14]. However, it has also been found to have drastic effects on virulence in vivo of B. melitensis Rev1 and B. ovis PA, in the absence of Omp31 [8, 17]. According to data we compiled in our previous and present studies, we conclude that the Omp31 does is not only involved in maintaining the integrity of the outer membrane, and the intracellular survival of the bacteria in macrophages and epithelial cells [19], but that it also plays an important role on the virulence of $B$. melitensis, since all the experimental groups that were inoculated with $B$. melitensis LVM31 mutant strain showed a decrease in splenic colonization without lesions or apparent histopathological changes in spleen compared to the control strains.

Another significant aspect is the persistence of the bacteria on spleen, which is an indicator of virulence or attenuation, and is regularly used in the quality control test of vaccines (residual virulence). Vaccine candidates are often analyzed in mice by determining splenic colonization ( $\mathrm{CFU} / \mathrm{ml}$ count) after the challenge test with the appropriate virulent Brucella doses at the precise post-vaccination times. Since most live or killed Brucella vaccines provide some degree of protection in mice, controls in mice immunized with reference vaccines (S19 or Rev1) are critical. Finally, the mice have been used successfully to evaluate prophylactic or therapeutic applications against brucellosis [32].

Based on these investigations we set ourselves the objective of evaluating the protection conferred in mice immunized with the mutant strain (LVM31), the vaccine strain (Rev1) and PBS (negative control) against the challenge with an infective dose of B. melitensis Bm133 wild-type strain. The results obtained in the present work showed that there was a lower statistically significant persistence of bacteria in the spleen of mice immunized with LVM31 mutant strain and Rev1 vaccine strain compared with the mice immunized with PBS $(p<0.05)$, and in terms of the splenic colonization in the vaccinated mice with LVM31 mutant strain and Rev1 vaccine strain, there were no statistically significant differences at any time post challenge with the virulent strain. According with these results, we conclude that $B$. melitensis LVM31 conferred a protective response similar to B. melitensis Rev1 vaccine strain against the challenge with $B$. melitensis $B m 133$ virulent strain.

The results obtained in the present work allow us to conclude that Omp31 protein plays an important role in bacterial virulence because there was a significant decrease in the splenic colonization and a lower persistence of the bacteria (residual virulence) in the spleen of both male and female BALB / c mice experimentally infected with LVM31 mutant strain compared to the control strains.

Finally, because the mutation of omp31 caused a significant attenuation of the bacteria in both in vitro and in vivo assays, B. melitensis LVM31 mutant strain could be considered as a potential vaccine candidate for the control of goat and sheep brucellosis.

\section{Acknowledgments}

This work was supported by PAPIIT IN-222516, PAPIIT IN-218519 and PAPIIT IN-209216, UNAM. The authors acknowledge Javier Nuñez for his technical support and Claudia Valdez for her support.

\section{Conflict of Interest}

The authors have no financial conflicts of interest to declare.

\section{References}

1. Pappas G. 2010. The changing Brucella ecology: novel reservoirs, new threats. Int. J. Antimicrob. Agents 36: S8-S11

2. Godfroid J, Garin-Bastuji B, Saegerman C, Blasco JM. 2013. Brucellosis in terrestrial wildlife. Rev. Sci. Tech. 32: 27-42.

3. Lalsiamthara J, Lee JH. 2017. Development and trial of vaccines against Brucella. J. Vet. Sci. 18(S1): 281-290.

4. Blasco J. 1997. A review of the use of B. melitensis Rev 1 vaccine in adult sheep and goats. Prev. Vet. Med. 31:275-283.

5. Blasco JM, Diaz R. Brucella melitensis Rev-1 vaccine as a cause of human brucellosis. Lancet 342(8874): 805.

6. Boussau B, Karlberg EO, Frank AC, Legault BA, Andersson SG. 2004. Computational inference of scenarios for a-proteobacterial genome evolution. Proc. Natl. Acad. Sci. USA 101: 9722-9727.

7. de Figueiredo P, Ficht TA, Rice-Ficht A, Rossetti CA, Adams LG. 2015. Pathogenesis and immunobiology of brucellosis: review of Brucella-Host Interactions. Am. J. Pathol. 185: 1505-1517. 
8. Caro-Hernández P, Fernández-Lago L, de Miguel MJ, Martín-Martín AI, Cloeckaert A, Grilló MJ, et al. 2007. Role of the Omp25/ Omp31 family in outer membrane properties and virulence of Brucella ovis. Infect. Immun. 75: 4050-4061.

9. Vizcaíno, N. and A. Cloeckaert. 2012. Biology and genetics of the Brucella outer membrane. Brucella molecular microbiology and genomics. 133-161

10. López-Goñi I, O’Callaghan D. 2012. Brucella: molecular microbiology and genomics. Horizon Scientific Press.

11. Byndloss MX, Tsolis RM. 2016. Brucella spp. virulence factors and immunity. Annu. Rev. Anim. Biosci. 4: 111-127.

12. Martín-Martín AI, Sancho P, Tejedor C, Fernández-Lago L, Vizcaíno N. 2011. Differences in the outer membrane-related properties of the six classical Brucella species. Vet. J. 189: 103-105.

13. Carroll JA, Coleman SA, Smitherman LS, Minnick MF. 2000. Hemin-binding surface protein from Bartonella quintana. Infect. Immun. 68: 6750-6757.

14. Delpino MV, Cassataro J, Fossati CA, Goldbaum FA, Baldi PC. 2006. Brucella outer membrane protein Omp31 is a haemin-binding protein. Microbes Infect. 8: 1203-1208.

15. Vizcaíno N, Caro-Hernández P, Cloeckaert A, Fernández-Lago L. 2004. DNA polymorphism in the omp25/omp31 family of Brucella spp.: identification of a 1.7-kb inversion in Brucella cetaceae and of a 15.1-kb genomic island, absent from Brucella ovis, related to the synthesis of smooth lipopolysaccharide. Microbes Infect. 6: 821-834.

16. Vizcaíno N, Verger JM, Grayon M, Zygmunt MS, Cloeckaert A. 1997. DNA polymorphism at the omp-31 locus of Brucella spp.: evidence for a large deletion in Brucella abortus, and other species-specific markers. Microbiology 143: 2913-2921.

17. Cloeckaert A, Jacques I, Grilló MJ, Marín CM, Grayon M, Blasco JM, et al. 2004. Development and evaluation as vaccines in mice of Brucella melitensis Rev. 1 single and double deletion mutants of the bp26 and omp31 genes coding for antigens of diagnostic significance in ovine brucellosis. Vaccine 22: 2827-2835.

18. Eschenbrenner M, Wagner MA, Horn TA, Kraycer JA, Mujer CV, Hagius S, et al. 2002. Comparative proteome analysis of Brucella melitensis vaccine strain Rev 1 and a virulent strain, 16M. J. Bacteriol. 184: 4962-4970.

19. Verdiguel-Fernández L, Oropeza-Navarro R, Basurto-Alcántara FJ, Castañeda-Ramírez A, Verdugo-Rodríguez A. 2017. Omp31 plays an important role on outer membrane properties and intracellular survival of Brucella melitensis in murine macrophages and HeLa cells. Arch. Microbiol. 199: 971-978.

20. Slack MP, Wheldon DB. 1978. Wheldon, A simple and safe volumetric alternative to the method of Miles, Misra and Irwin for counting viable bacteria. J. Med. Microbiol. 11: 541-545.

21. NOM-041-ZOO-1995, N.O.M., Campaña contra la Brucelosis de los Animales. Diario Oficial de la Federación, México, DF.

22. Jacques I, Verger JM, Laroucau K, Grayon M, Vizcaino N, Peix A, et al. 2007. Immunological responses and protective efficacy against Brucella melitensis induced by bp26 and omp31 B. melitensis Rev. 1 deletion mutants in sheep. Vaccine 5: 794-805.

23. Grilló MJ, Blasco JM, Gorvel JP, Moriyón I, Moreno E. 2012. What have we learned from brucellosis in the mouse model? Vet. Res. 43: 29.

24. Parkinson CM, O'Brien A, Albers TM, Simon MA, Clifford CB, Pritchett-Corning KR. 2011. Diagnostic necropsy and selected tissue and sample collection in rats and mice. J. Vis. Exp. 7: (54). pii:2966.

25. von Bargen, K., J.-P. Gorvel, S.P. Salcedo. 2012. Internal affairs: investigating the Brucella intracellular lifestyle. FEMS Microbiol. Rev. 36: 533-562.

26. De Bolle X, Crosson S, Matroule JY, Letesson JJ . 2015. Brucella abortus cell cycle and infection are coordinated. Trends Microbiol. 23: $812-821$

27. Seleem MN, Boyle SM, Sriranganathan N. 2008. Brucella: a pathogen without classic virulence genes. Vet. Microbiol. 129: 1-14.

28. Roop RM 2nd, Bellaire BH, Valderas MW, Cardelli JA. 2004. Adaptation of the Brucellae to their intracellular niche. Mol. Microbiol. 52: $621-630$.

29. Castañeda-Ramírez A, González-Rodríguez D, Hernández-Pineda JA, Verdugo-Rodríguez A. 2015. Blocking the expression of syntaxin 4 interferes with initial phagocytosis of Brucella melitensis in macrophages. Can. J. Vet. Res. 79: 39-45.

30. Celli J. 2006. Surviving inside a macrophage: The many ways of Brucella. Res. Microbiol. 157: 93-98.

31. Comerci DJ, Martínez-Lorenzo MJ, Sieira R, Gorvel JP, Ugalde RA. 2001. Essential role of the VirB machinery in the maturation of the Brucella abortus-containing vacuole. Cell. Microbiol. 3: 159-168.

32. Teane Silva, Erica Costa, Tatiane Paixao, Renee Tsolis, Renato Santos. 2011. Laboratory animal models for brucellosis research. J. Biomed. Res Int. Article ID 51823.

33. Rajashekara G, Glover DA, Krepps M, Splitter GA. 2005. Temporal analysis of pathogenic events in virulent and avirulent Brucella melitensis infections. Cell. Microbiol. 7: 1459-1473.

34. Rajashekara G, Glover DA, Banai M, O'Callaghan D, Splitter GA. 2006. Attenuated bioluminescent Brucella melitensis mutants GR019 (virB4), GR024 (galE), and GR026 (BMEI1090-BMEI1091) confer protection in mice. Infect. Immun. 74: 2925-2936.

35. Wang Z, Wang SS, Wang GL, Wu TL, Lv YL, Wu QM. 2014. A pregnant mouse model for the vertical transmission of Brucella melitensis. Vet. J. 200: 116-121.

36. Sancho P, Tejedor C, Sidhu-Muñoz RS, Fernández-Lago L, Vizcaíno N. 2014. Evaluation in mice of Brucella ovis attenuated mutants for use as live vaccines against B. ovis infection. Vet. Res. 45: 61.

37. Martín-Martín AI, Caro-Hernández P, Orduña A, Vizcaíno N, Fernández-Lago L. 2008. Importance of the Omp25/Omp31 family in the internalization and intracellular replication of virulent B. ovis in murine macrophages and HeLa cells. Microbes Infect. 10: $706-$ 710

38. Zhang K, Wang H, Guo F, Yuan L, Zhang W, Wang Y. 2016. OMP31 of Brucella melitensis 16M impairs the apoptosis of macrophages triggered by TNF- $\alpha$. Exp. Ther. Med. 12: 2783-2789.

39. Vizcaíno N, Cloeckaert A, Zygmunt MS, Dubray G. 1996. Cloning, nucleotide sequence, and expression of the Brucella melitensis omp31 gene coding for an immunogenic major outer membrane protein. Infect. Immun. 64: 3744-3751. 